\title{
Self-Ligating Bracket with Herbal Dentifrices-Comparative Clinical and Microbiological Study
}

\author{
Dr. Aseem Sharma ${ }^{1}$, Dr. Sachin Upadhyay ${ }^{2}$, Dr. Mandeep Nain ${ }^{3}$, Dr. Yatharth Goel ${ }^{4}$, Dr. Neelam Chauhan ${ }^{5}$, Dr. Deepak \\ Phor $^{6}$ \\ ${ }^{1,2}$ Senior Lecturer in Department of Orthodontics and Dentofacial Orthopedics at Himachal Institute of Dental Sciences Paonta Sahib, Himachal \\ Pradesh India \\ ${ }^{3}$ Post Graduate student in the Department of Prosthodontics, DAV Dental College, Yamuna Nagar \\ ${ }^{4}$ Director at Dantam Dental Solutions 44, Civil lines, Jadugar Road, Roorkee (U.K) India \\ ${ }^{5}$ Consultant Orthodontist at Kullu Smiles, Kullu Himachal Pradesh India \\ ${ }^{6}$ Senior Lecturer in Department of Orthodontics and Dentofacial Orthopedics at Yamuna Dental College, Yamunanagar Haryana India
}

DOI: 10.36348/SJODR.2019.v04i09.011 | | Received: 11.09.2019| Accepted: 20.09.2019| Published: 30.09 .2019

*Corresponding author: Dr. Sachin Upadhyay

\section{Abstract}

Background: To ascertain if herbal dentifrices have an effect on Streptococcus mutans count in orthodontic patients with Self ligating brackets. Material and method: patient had tooth No's 25 included in the study with SLB bracket bonded. Dentifrices tested were Herbal based. Conventional tooth paste was considered as control group. Result: Paired T test compared the means of Streptococcus mutans count around SLB bracket at different time intervals. Conclusion: This shows self-ligating bracket has statistically significant reduction of Streptococcus mutans with herbal toothpaste.

Keywords: SLB, Herbal, Streptococcus mutans.

Copyright @ 2019: This is an open-access article distributed under the terms of the Creative Commons Attribution license which permits unrestricted use, distribution, and reproduction in any medium for non-commercial use (NonCommercial, or CC-BY-NC) provided the original author and source are credited.

\section{INTRODUCTION}

Streptococcus mutans is a potent initiator of caries because there are a variety of virulence factors unique to the bacterium and play an important role in caries initiation. Firstly, Streptococcus mutans is an anaerobic bacterium known to produce lactic acid as part of its metabolism. Secondly, there is the ability of Streptococcus mutans to bind to tooth surfaces in the presence of sucrose by the formation of water-insoluble glucans, a polysaccharide that aids in binding the bacterium to the tooth Unlike the majority of oral microorganisms, Streptococcus mutans thrives under acidic conditions and becomes the dominant bacterium in cultures with permanently reduced $\mathrm{pH}$ the meswak or Sewak is a tooth cleaning twig produced from a twig of the Salvadora persics tree (called arak in Arabic and peelu in Pakistan). Meswak stick features a long, documented history and is known for its remedial advantages. The World Health Organization (WHO) endorsed the usage of the meswak for its oral cleanliness features and scientific research therefore validating its anti-bacterial and plaque preventing qualities. Meswak is an eco-friendly, natural and cost effective way to maintain oral hygiene. Due to free availability and exclusive chemical structure the usage of meswak stick and other natural herbs are growing at a rapid speed in both developing and developed nations. Research has confirmed that meswak is as useful as, or may be even better than the current day common dental hygiene aids. The World Health Organization (WHO) has endorsed and suggested the usage of meswak as a good tool for dental hygiene. Hence, this study of microbiological assay of Streptococcus mutans with an objective to study the performance and measure the efficacy of toothpastesNeem, Meswak, Babool and Pomegranate based herbal toothpaste with SLB Bracket is done.

\section{AIM AND OBJECTIVES}

To ascertain if herbal dentifrices have an effect on Streptococcus mutans count in orthodontic patients with Self ligating brackets.

\section{MATERIAL AND METHOD}

\section{Nature of Study}

Randomized, prospective, cross sectional single blinded microbiological assay study with each patient acting his /her own control in this study. 
Area of Study

Department of Orthodontics and Dentofacial Orthopedics, Divya Jyoti College of Dental Sciences and Research and Microbiological Assay were conducted in Divya Jyoti Hospital.

\section{Ethical Clearance}

This study was approved by Institutional Committee (IEC No DJD/IEC/2014/A-001). A written consent was taken from each participating subject.

\section{Inclusion criteria}

- Patient with similar socioeconomic strata \& common food habits.

- Patients free of oral/parental antibiotics for one month.

- No periodontal \& systemic disorders

- Patients with no crowding and who have had alignment and leveling completed.

\begin{tabular}{|c|l|c|}
\hline S.No & \multicolumn{1}{|c|}{ Dentifrices } & Cotails \\
\hline $\mathbf{1}$ & $\begin{array}{l}\text { Himalaya Herbals Dentifrice } \\
\text { (Himalaya Global Holding Ltd.) Containing Neem, Meswak Babool and Pomegranate }\end{array}$ & Y (Blue) \\
\hline
\end{tabular}

\begin{tabular}{|c|c|}
\multicolumn{2}{c}{ Bracket Type } \\
\hline S. No & Bracket type \\
\hline 1 & Passive Self Ligating Bracket \\
& [ Empower 0.22 MBT American \\
& Orthodontics] \\
\hline
\end{tabular}

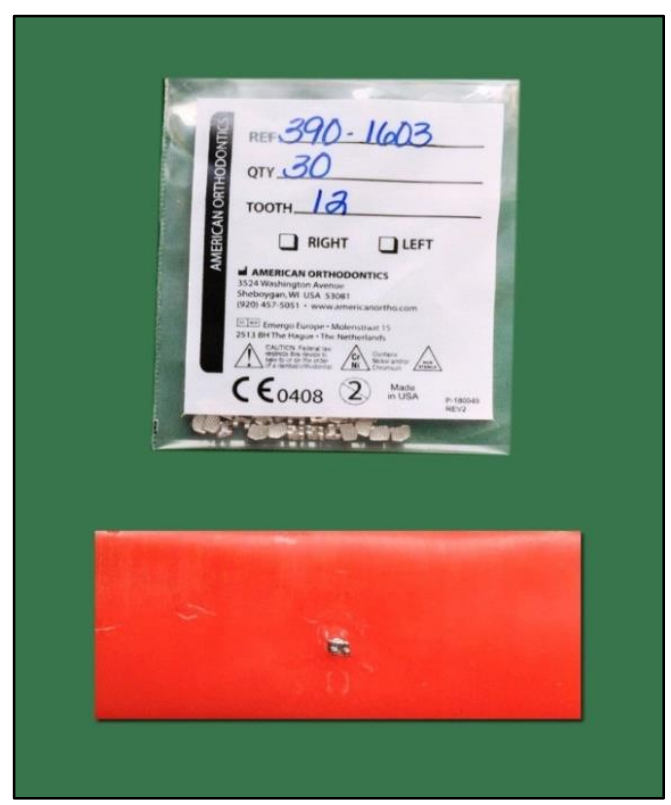

\section{SLB BRACKET}

\section{Steps and Time Interval of Study}

- $\quad$ Each group consists of 30 teeth with 30 brackets to be tested.

- Each patient served as his/her own control as 1 types of bracket were tested in the same mouth at the same time period.

- Each patient had tooth No's 25 included in the study with SLB bracket bonded.

- Dentifrices tested were Herbal based.

- The dentifrices were dispensed into $5 \mathrm{ml}$ bottles coded as Y for Herbal toothpaste -Neem, Babool, Meswak and Pomegranate. Color Coding of Dentifrices

- Conventional tooth paste was considered as control group.

\begin{tabular}{|c|c|c|c|}
\hline S. No & N & Type & $\begin{array}{c}\text { Bracket Bonded } \\
\text { on } \\
\text { Tooth Number }\end{array}$ \\
\hline I & 30 & $\begin{array}{c}\text { Self-Ligating } \\
\text { passive MBT }\end{array}$ & 25 \\
\hline
\end{tabular}

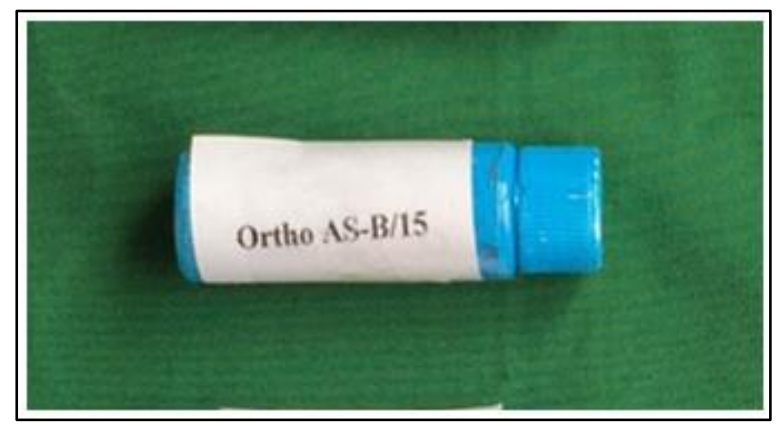

\begin{tabular}{|c|c|c|}
\hline CODES & COLOR & DENTIFRICES \\
\hline $\mathbf{Y}$ & $\begin{array}{c}\text { Silvervff } \\
\text { Blue }\end{array}$ & $\begin{array}{c}\text { Herbal Based Toothpaste } \\
\text { (Herbal Global Holding Ltd } \\
\text { Toothpaste) }\end{array}$ \\
\hline
\end{tabular}

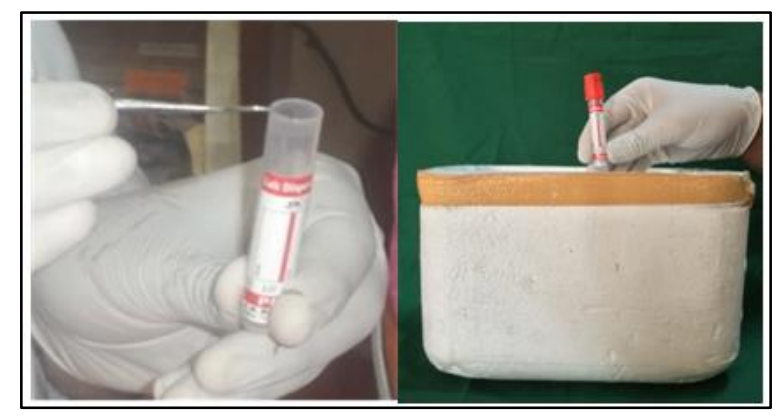

Ice Box Plaque Collection and Transportation

\section{Plaque collection and transportation}

- Plaque sample placed in $5 \mathrm{ml}$ sterilized vials with $1 \mathrm{ml}$ distill water.

- Sterilized vials were transported in icebox to the lab.

- The bacteriological study was conducted by Dilution Plating Method.

- The growth media used was Mutans-Sanguis Agar. 


\section{Oral Hygiene Instructions}

- The subjects were given oral hygiene instructions $\&$ requested to refrain from using any other oral hygiene products like mouthwash etc.

- The subjects were instructed to follow standard oral hygiene regime which included brushing twice a day with toothpaste as prescribed in the study regime.

- The patients were advised to rinse thoroughly after every meal.

Table Shows: Time Interval of Tooth Paste Usage

\begin{tabular}{|l|l|}
\hline TOOTHPASTE & TIME INTERVAL \\
\hline Baseline without use of study Dentifrices & $1^{\text {st }}$ to $2^{\text {nd }}$ Day \\
\hline Herbal (Y) & $3^{\text {rd }}$ to 8 th Day \\
\hline
\end{tabular}

Table Shows: Time Interval of Plaque Collection Plaque Collection Method

\begin{tabular}{|c|c|c|}
\hline Sample Count & Time Interval & Day Count \\
\hline $\begin{array}{c}\text { Sample No.1 } \\
\text { (baseline without use of study dentifrices) }\end{array}$ & $\begin{array}{c}\mathbf{( T}_{\mathbf{1}} \text { ) } \\
\text { (Start of study ) }\end{array}$ & Day : 1 \\
\hline Sample No.2 & $\mathbf{T}_{\mathbf{2}}$ & Day : 3 \\
\hline Sample No.3 & $\mathbf{T}_{\mathbf{3}}$ & Day : 8 \\
\hline
\end{tabular}

- Patients were requested to refrain from eating or drinking 1 hour prior to sample collection.

- Plaque sample was collected by Four Pass Technique at midmorning (11 a.m.).

- In this technique the explorer tip is moved around the circumference of the bracket at the bracket tooth interface.

- Four passes, along the tooth at the bracket interface at the gingival, mesial, distal, and occlusal aspects are done to avoid overloading the instrument tip.

- This is considered an effective method of obtaining the total plaque .Plaque samples were placed in sterilized vials having distilled water in it.

\section{Laboratory Equipment's}

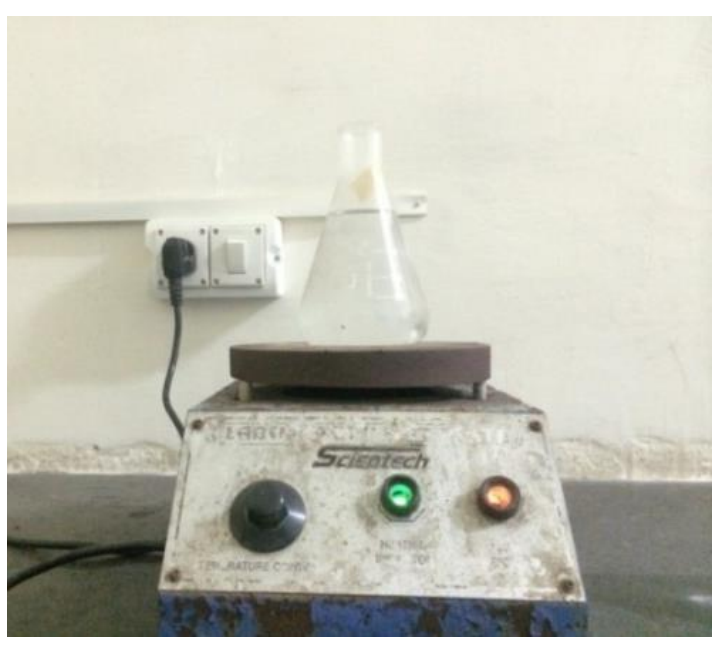

Hot Plate

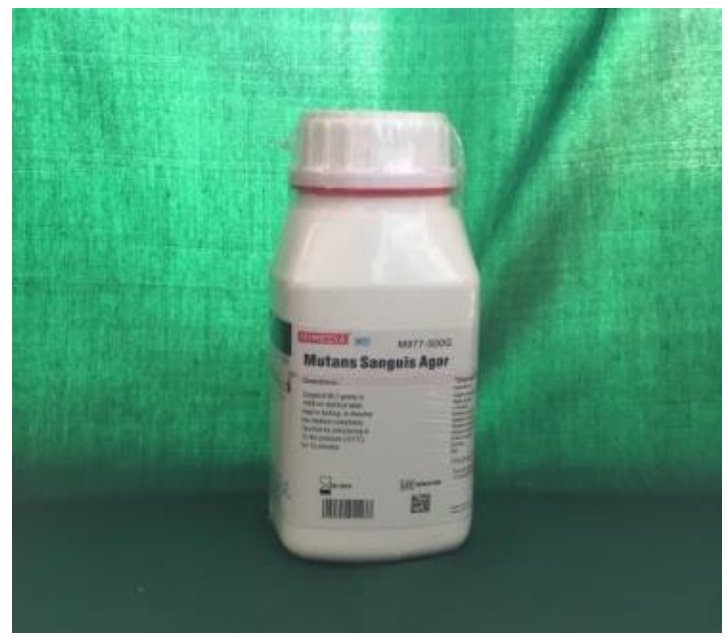

Mutans Sanguis Agar

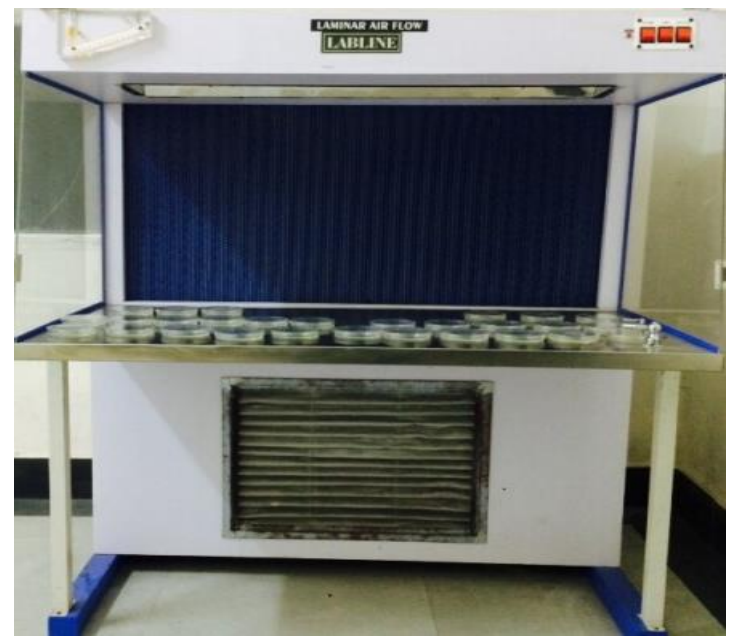

Laminar Air Flow 
Aseem Sharma et al; Saudi J Oral Dent Res, Sep 2019; 4(9): 626-630

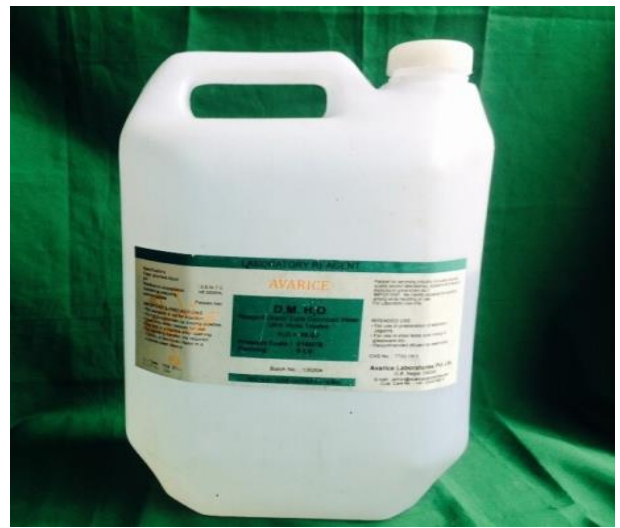

Distilled Water

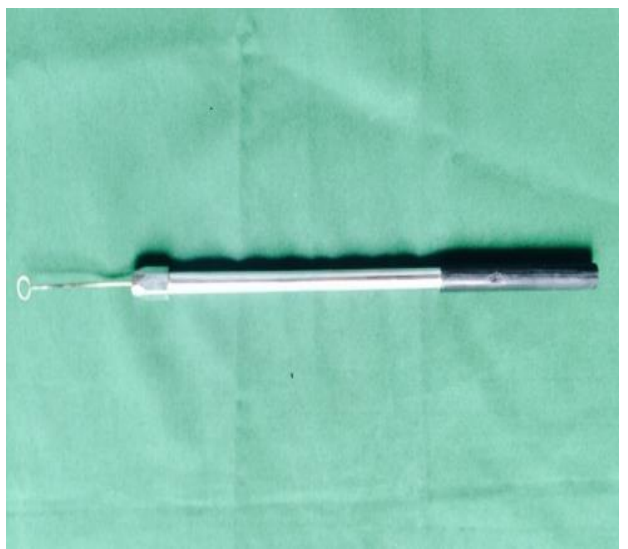

Wire Loop

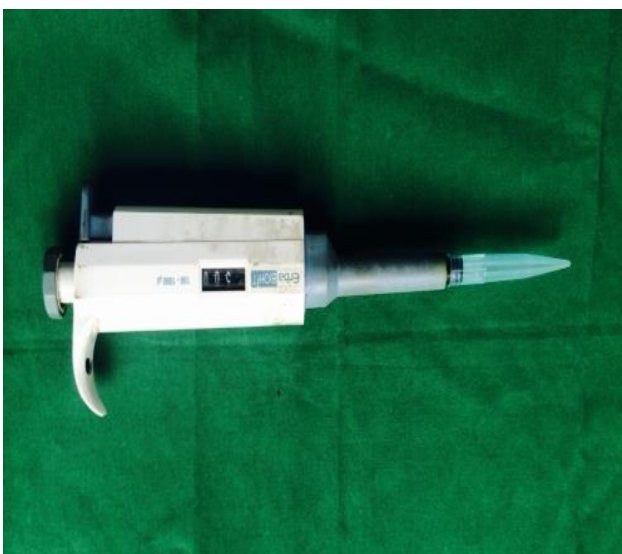

Micropipette

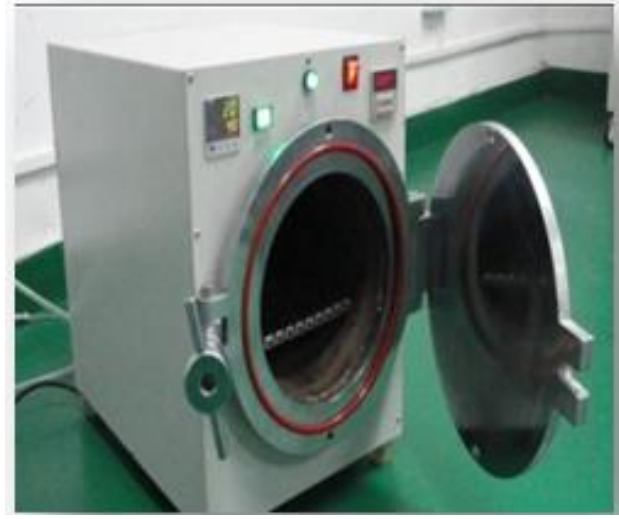

Petridishes Placed Inside Incubator

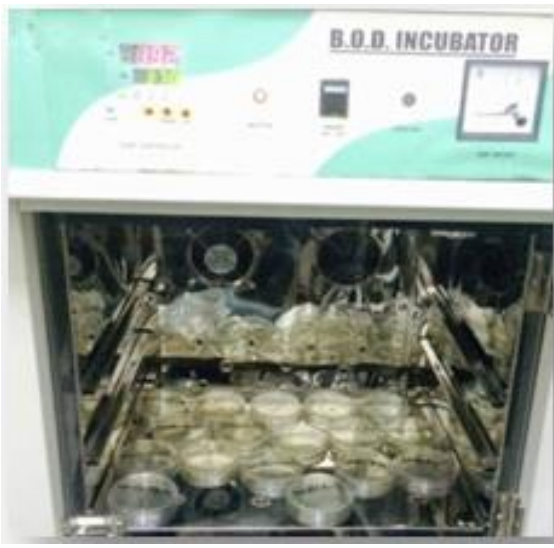

Petridishes Placed Inside Incubator

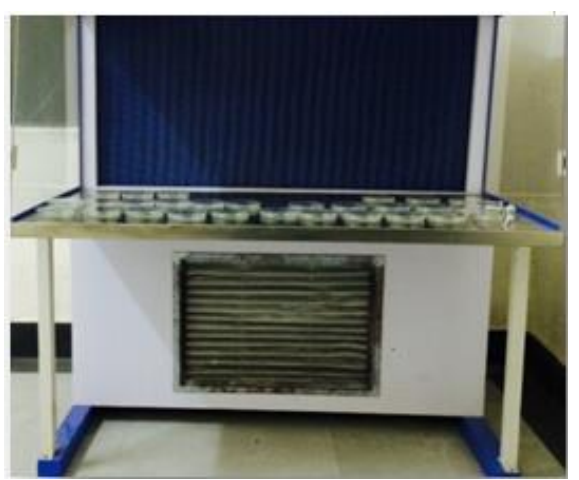

Incubator

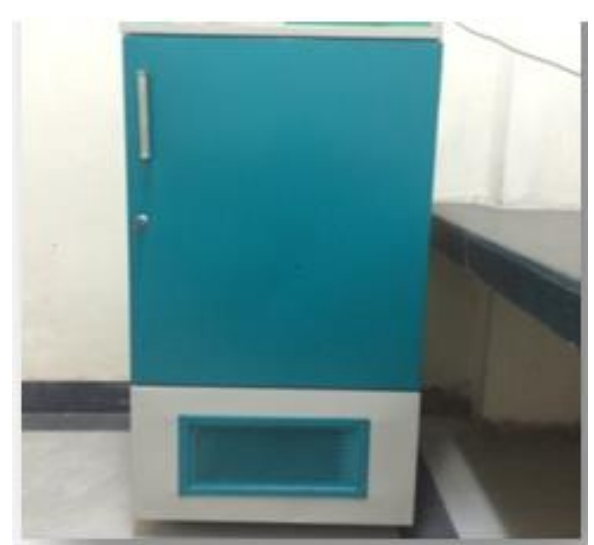

Solidification of Agar Medium in Laminar Air Flow

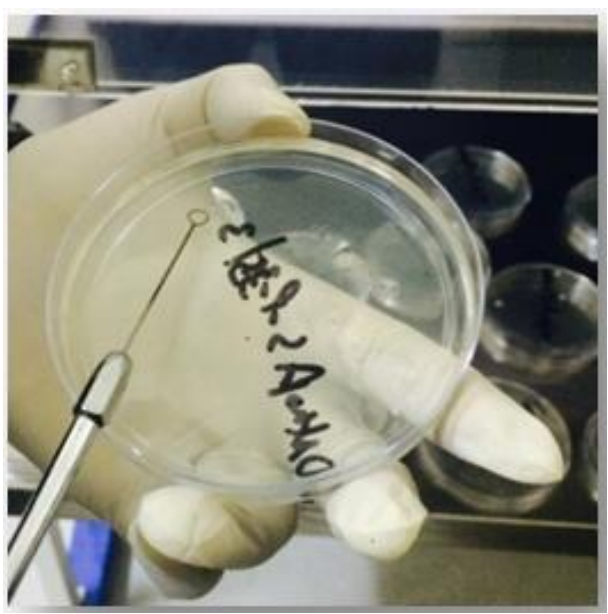

Spreading of Plaque Sample over Petridish 
Aseem Sharma et al; Saudi J Oral Dent Res, Sep 2019; 4(9): 626-630

\begin{tabular}{|c|l|}
\hline S.No & Item \\
\hline $\mathbf{1}$ & Autoclave \\
\hline $\mathbf{2}$ & Hotplate \\
\hline $\mathbf{3}$ & Petridish \\
\hline $\mathbf{4}$ & Micropipette \\
\hline $\mathbf{5}$ & Laminar flow Cabinet \\
\hline $\mathbf{6}$ & Conical flask \\
\hline $\mathbf{7}$ & Cotton Plug \\
\hline $\mathbf{8}$ & Sterilized Wire loop \\
\hline $\mathbf{9}$ & Incubator \\
\hline $\mathbf{1 0}$ & Disposable gloves \\
\hline $\mathbf{1 1}$ & U shape flask \\
\hline $\mathbf{1 2}$ & Disposable Mouth mask \\
\hline
\end{tabular}

\section{RESULT}

Table Shows: Comparison of Means of Streptococcus mutans Count at Different Time Intervals around Self ligating Bracket by Paired T - Test.

\begin{tabular}{|l|l|l|c|c|c|c|}
\hline \multicolumn{2}{|c|}{ Days } & $\begin{array}{c}\text { Mean } \\
\text { difference }\end{array}$ & T & d.f. & P value \\
\hline $\begin{array}{l}\text { Day } \\
\mathbf{1}\end{array}$ & - & $\begin{array}{l}\text { Day } \\
\mathbf{3}\end{array}$ & .00000 & .000 & 29 & $1.000^{*}$ \\
\hline $\begin{array}{l}\text { Day } \\
\mathbf{3}\end{array}$ & - & $\begin{array}{l}\text { Day } \\
\mathbf{8}\end{array}$ & 1.03333 & 6.656 & 29 & $0.000 * * *$ \\
\hline
\end{tabular}

$0.05, *$ Not Significant $\mathrm{p}>0.05$

- $\quad$ Paired T test compared the means of Streptococcus mutans count around SLB bracket at different time intervals.

- Difference between Day 3 \& Day 8 with herbal dentifrice was highly significant statistically

- Difference between Day 1 \& Day 3 was not statistically significant.

- The mean difference between Day 3 \& Day 8 is 0.13333 .

\section{CONCLUSION}

- This shows self-ligating bracket has statistically significant reduction of Streptococcus mutans with herbal toothpaste.

\section{DISCUSSION}

Microorganisms play a major role in causation of WSL and dental caries. Entire removal of microorganism from the oral cavity is difficult but their count can be reduced with the help of various preventive measures so that it becomes less cariogenic. The market is flooded with numerous bracket types of different biomaterials. Literature evidences that adherence of plaque to the fixed appliance is largely contributed by the bracket material [7] as it could play a role in the degree of bacterial adhesion and plaque accumulation as well as in the risk of development of WSL. The initial affinity of bacteria to solid surfaces is due mostly to electrostatic and hydrophobic interactions. Surfaces with high surface free energy more easily attract bacteria such as S. mutans[3]. Currently Self Ligating Brackets are being driven by manufacturers as having a hygiene advantage, while many studies have reported in the contrary [7]. The results of the current research study showed significant reduction around SLB bracket with herbal toothpaste. The value of current study suggests that herbal dentifrices have good antimicrobial effects on caries producing bacteria, thus can be used in orthodontic patients and as a regular home care preventive aid in combating dental caries.

\section{REFERENCES}

1. Ahn, S. J., Lim, B. S., Yang, H. C., \& Chang, Y. I. (2005). Quantitative analysis of the adhesion of cariogenic streptococci to orthodontic metal brackets. The Angle Orthodontist, 75(4), 666-671.

2. Jurela, A., Repic, D., Pejda, S., Juric, H., Vidakovic, R., Matic, I., \& Bosnjak, A. (2012). The effect of two different bracket types on the salivary levels of $\mathrm{S}$ mutans and $\mathrm{S}$ sobrinus in the early phase of orthodontic treatment. The Angle Orthodontist, 83(1), 140-145.

3. Papaioannou, W., Gizani, S., Nassika, M., Kontou, E., \& Nakou, M. (2007). Adhesion of Streptococcus mutans to different types of brackets. The Angle Orthodontist,77(6), 10901095.

4. Sowmya Kote, D., \& Sunder Kote, D. (2011). Effect of pomegranate juice on dental plaque microorganisms (streptococci and lactobacilli). Ancient science of life, 31(2), 49.

5. Ahn, S. J., Lim, B. S., Yang, H. C., \& Chang, Y. I. (2005). Quantitative analysis of the adhesion of cariogenic streptococci to orthodontic metal brackets. The Angle Orthodontist, 75(4), 666-671.

6. Halawany, H. S. (2012). A review on miswak (Salvadora persica) and its effect on various aspects of oral health. The Saudi dental journal, 24(2), 6369.

7. Pandis, N., Papaioannou, W., Kontou, E., Nakou, M., Makou, M., \& Eliades, T. (2009). Salivary Streptococcus mutans levels in patients with conventional and self-ligating brackets. The European Journal of Orthodontics, 32(1), 94-99.

8. Misra, V., Ahuja, N. K., Gupta, N., \& Raghav, P. (2012). Effect of Two Different Materials Used For Arch Wire Ligation on Microbial Colonization. Indian Journal of Dental Sciences, 4(1). 